\title{
Update on the management of ulcerative colitis: treatment and maintenance approaches focused on $\mathrm{MMX}^{\circledR}$ mesalamine
}

This article was published in the following Dove Press journal:

Clinical Pharmacology:Advances and Applications

24 July 2012

Number of times this article has been viewed

\author{
Kavinderjit Nanda \\ Alan C Moss \\ Center for Inflammatory Bowel \\ Disease, BIDMC/Harvard Medical \\ School, Boston, MA, USA
}

Correspondence: Alan C Moss BIDMC, 330 Brookline Ave, Boston, MA 02215, USA

$\mathrm{Tel}+\mid \mathrm{I} 6176673197$

Fax +| 6I7667 II7|

Email amoss@bidmc.harvard.edu

\begin{abstract}
Ulcerative colitis (UC) is a chronic inflammatory disease of the colon that typically manifests as diarrhea, abdominal pain, and bloody stool. Complications, such as colorectal cancer and extraintestinal manifestations, may also develop. The goals of management are to induce and maintain clinical remission and to screen for complications of this disease. Mesalamine is a 5-aminosalicylic acid compound that is the first-line therapy to induce and maintain clinical remission in patients with mild-to-moderate UC. For patients who are refractory to mesalamine or have more severe disease, steroids, azathioprine/mercaptopurine, cyclosporine, or infliximab may be used, induce and/or maintain remission. The various formulations of mesalamine available are primarily differentiated by the methods of delivery of the active compound of the drug to the colon. Mesalamine with Multi-Matrix System ${ }^{\circledR}$ (MMX) technology (Cosmo SpA, Milan, Italy) is an oral (1.2 g), once-daily tablet formulation of mesalamine used for the treatment of UC (Lialda ${ }^{\circledR}$ or Mezavant ${ }^{\circledR}$, Shire Pharmaceuticals Inc, Wayne, PA). In clinical studies, MMX mesalamine (taken as a once-daily dose of 2.4 or $4.8 \mathrm{~g}$ ) effectively induced and maintained clinical remission in patients with active mild-to-moderate UC. The overall safety profile of MMX mesalamine is similar to other oral mesalamine formulations. The use of such once-daily formulations has led to intense interest in whether simplified pill regimens can improve patient adherence to mesalamine therapy.
\end{abstract}

Keywords: mesalamine, 5-ASA, ulcerative colitis, inflammatory bowel disease

Ulcerative colitis (UC) is a chronic inflammatory disorder of the gastrointestinal tract of unknown etiology. $\mathrm{UC}$ is characterized by recurring episodes of inflammation limited to the mucosal and submucosal layer of the colon. It invariably involves the rectum and may extend in a proximal and continuous fashion to involve other portions of the colon. ${ }^{1}$ The onset and relapse of the disease may be triggered by environmental factors that transiently break the mucosal barrier, stimulate immune responses, or alter the balance between beneficial and pathogenic enteric bacteria. ${ }^{2}$ Patients with UC follow a relapsing and remitting clinical course, with symptoms of bloody diarrhea, rectal urgency, and abdominal pain during disease activity. ${ }^{3}$ In addition, patients may suffer from extraintestinal manifestations of UC, including episcleritis, scleritis, uveitis, peripheral arthropathies of small and large joints, erythema nodosum, pyoderma gangrenosum, axial arthropathies, sacroiliitis, ankylosing spondylitis, and primary sclerosing cholangitis. ${ }^{4}$ There is an increased risk for colorectal cancer (CRC) with longstanding inflammation, with risks reported at $0.5 \%-1 \%$ per year. ${ }^{5}$ These incidence rates corresponded to cumulative probabilities of $2 \%$ by 10 years, $8 \%$ by 20 years, and $18 \%$ by 30 years. ${ }^{6}$ 
Ulcerative colitis most commonly affects teenagers and young adults (onset between ages 15 and 40 years), but can occur in any age group. Breakdown by racial and ethnic subgroups indicate that higher rates of inflammatory bowel disease (IBD) occur in people of Caucasian and Ashkenazi Jewish origin than in individuals of other backgrounds. ${ }^{7}$ It has a prevalence of 238 per 100,000 (95\% confidence intervals [CI]: 234-241) in the United States adult population and an incidence rate of 2.2 to 14.3 cases per 100,000 person-years in North America. ${ }^{8}$ Although the incidence rates of UC increased after 1940, they have remained stable over the past 30 years. ${ }^{1}$ Since 1991, the prevalence of UC has decreased by $7 \% .{ }^{1}$ The rates are highest in northern climates and in well-developed areas of the world, such as North America, Great Britain, and Scandinavia, and lowest in southern climates and in underdeveloped areas. ${ }^{9}$ The disease has become more common in the developing world as different countries adopt Western lifestyles. ${ }^{8}$ Studies of migrant populations and populations of developing countries demonstrated a recent, slow increase in the incidence of UC. ${ }^{10}$ Such epidemiologic observations indicated that there are strong environmental influences on IBD, which is supported by the relatively low concordance rate of $10 \%$ in identical twins. ${ }^{11}$ Differences in incidence across age, time, and geographic region suggest that environmental factors significantly modify the expression of UC. The strongest protective environmental factors identified are cigarette smoking and appendectomy. ${ }^{8}$ Former smokers are approximately 1.7 times more likely to develop the disease than those who have never smoked. Whether other factors, such as diet, oral contraceptives, perinatal/childhood infections, or atypical mycobacterial infections, play a role in expression of inflammatory bowel disease remains unclear.

\section{Current management of ulcerative colitis}

The goal of managing patients with UC is to induce and maintain clinical and endoscopic remission and to prevent or treat complications. The majority of patients are successfully managed with pharmacologic therapies, but surgical resection of the colon (colectomy) may be needed for refractory disease or complications, such as strictures or carcinoma. Conventional medical therapies for UC include 5-aminosalicylic acid (5-ASA), corticosteroids, thiopurines, and anti-tumor necrosis factor (TNF) agents. ${ }^{12}$ The initial therapeutic approach depends upon both the extent of colonic involvement and the severity of the disease process at presentation. Medical management usually involves a "step-up" approach, starting with topical or oral agents and progressing to more complex agents, with risk of more serious adverse effects, in those who do not respond to firstline agents. ${ }^{3}$ Since there is no known cure for UC (except a colectomy), most patients take lifelong maintenance medical therapy to prevent disease relapse.

Medical therapy involves agents used to achieve clinical response and remission (induction agents) and those used to maintain clinical remission (maintenance agents), although many drugs can be used for both situations. In patients with "distal" disease (rectum and sigmoid colon), topical therapy is the preferred choice of treatment. Suppositories are effective in the rectosigmoid area, whereas enemas can reach the splenic flexure. For active distal disease, the American College of Gastroenterology (ACG) Practice Guidelines recommend topical therapy with mesalamine, hydrocortisone, or budesonide. ${ }^{3}$ Topical mesalamine agents are superior to topical steroids or oral aminosalicylates in this setting. ${ }^{13}$ A systematic review of topical 5-ASA has confirmed the efficacy of rectal-5-ASA in inducing remission and that it is superior to rectal corticosteroids or placebo. ${ }^{14}$ Several metaanalyses have concluded that rectal 5-ASA was superior to placebo for inducing remission and for maintenance of remission. ${ }^{15-17}$

Oral mesalamine or sulfasalazine are 5-ASAs that are usually required in patients with disease extending beyond the sigmoid colon. The ACG recommends that patients with mild to moderate active extensive colitis should begin therapy with oral sulfasalazine or mesalamine in doses up to $4.8 \mathrm{~g}$ per day. ${ }^{3}$ In a series of meta-analyses by Sutherland and colleagues ${ }^{18,19}$ and Ford et al, ${ }^{20}$ oral 5-ASAs were shown to be more effective than placebo in induction and maintenance of remission in UC. Efficacy rates reported for all 5-ASA agents are similar, although few comparative studies have been performed. One RCT reported no difference between similar doses of $\mathrm{pH}$-dependent release and timed-release mesalamine formulations in induction of remission of active UC. ${ }^{21}$ There appears to be a dose-dependent effect with mesalamine, as doses $>2 \mathrm{~g}$ /day were found to have better efficacy compared to $<2 \mathrm{~g}$ /day in induction and maintenance. ${ }^{20}$ Although multiple daily doses have been used in initial trials for induction of remission, a once-daily dose of mesalamine is as effective as conventional dosing schedules for the maintenance of remission in UC. ${ }^{22-24}$ Clinical response rates of $60 \%-70 \%$ and clinical remission rates of $40 \%-70 \%$ have been reported in various studies from 6 to 8 weeks. ${ }^{18,20}$ Meta-analyses of these induction studies concluded that the mean remission rate with mesalamine was $42 \%$, compared with $24 \%$ in placebo-treated patients. ${ }^{20}$ 
Once clinical remission has been achieved, mesalamine suppositories or enemas are recommended for maintenance of remission in patients with distal disease and oral mesalamine is recommended for those with more extensive disease. ${ }^{12}$ Maintenance of remission rates of $61 \%-68 \%$ at 12 months with oral mesalamine has been reported. ${ }^{25,26} \mathrm{~A}$ meta-analysis by Ford et al reported that $42 \%$ of prescribed patients relapsed compared with $65 \%$ of patients taking placebo after 6 to 12 months of therapy. ${ }^{20}$ Combined oral and rectal 5-ASA therapy appeared superior to oral 5-ASAs for the induction of remission of mildly to moderately active left-sided UC, and intermittent topical 5-ASAs appeared superior to oral 5-ASAs for preventing relapse of quiescent left-sided UC. ${ }^{16}$

The US Food and Drug Administration (FDA)-approved oral doses for induction of remission are as follows: Asacol $^{\mathbb{B}}$ (Warner Chilcott Company, Dublin, Ireland) 800 g three times daily, Asacol HD $1.6 \mathrm{~g}$ three times daily, and Pentasa ${ }^{\circledR}$ (Shire, Wayne, PA) $4 \mathrm{~g}$ daily. The US FDA-approved doses for maintaining remission are as follows: Asacol $1.6 \mathrm{~g}$ daily in divided doses, Pentasa $4 \mathrm{~g}$ daily, and Apriso ${ }^{\circledR}$ (Salix Pharmaceuticals, Morrisville, NC) $1.5 \mathrm{~g}$ daily. The recommended dosage of Multi-Matrix System ${ }^{\circledR}$ (MMX; Cosmo SpA, Milan, Italy) mesalamine (Lialda ${ }^{\circledR}$; Shire Pharmaceuticals Inc, Wayne, PA) is $2.4 \mathrm{~g}$ or $4.8 \mathrm{~g}$ once daily for up to 8 weeks as induction therapy and $2.4 \mathrm{~g}$ once daily as maintenance therapy.

Data from ASCEND 1 and 2 trials with oral mesalamine (Asacol) reported that times to resolution and improvement of both rectal bleeding and stool frequency were shorter with $4.8 \mathrm{~g}$ /day than $2.4 \mathrm{~g}$ /day (resolution, 19 vs 29 days; $P=0.020) .{ }^{27}$ Endoscopic healing rates (improvement in or resolution of mucosal damage seen at endoscopy) occur in $30 \%-80 \%$ of patients treated with mesalamine within 6 to 8 weeks. ${ }^{28}$ In a pooled retrospective analysis of the ASCEND 1 and 2 data in UC patients receiving delayed release oral mesalamine (Asacol) at week $6,80 \%$ on $4.8 \mathrm{~g}$ /day compared to $68 \%$ on $2.4 \mathrm{~g} /$ day $(P=0.012)$ achieved endoscopic healing. ${ }^{29} \mathrm{~A}$ post-hoc analysis of trial data of topical mesalamine suspension concluded that this mesalamine delivery method also led to earlier symptom improvement and endoscopic mucosal healing of distal colitis when compared to placebo or oral mesalamine alone. ${ }^{30}$

Oral steroids are generally reserved for patients who are refractory to oral 5-ASA in combination with topical therapy and have troublesome symptoms that require quick resolution. Corticosteroids are not efficacious in maintenance treatment and are not recommended for long-term treatment. ${ }^{31}$ Patients who cannot be weaned off corticosteroids may need the introduction of azathioprine, 6-mercaptopurine (6MP), or infliximab as a steroid-sparing agent to avoid long-term corticosteroid use. Azathioprine and 6-MP are effective in maintaining remission in patients with moderate-to-severe disease, but they are not suitable for the induction of remission due to the prolonged time to take effect (8-12 weeks). ${ }^{3}$ The role of methotrexate in UC is still unclear and is a matter for ongoing study. ${ }^{32}$ Infliximab is an effective treatment for patients with moderate-to-severe disease, those who are steroid-refractory or steroid dependent despite adequate doses of a thiopurine, or who are intolerant of these medications due to side effects. ${ }^{33}$ Selective leukocytapheresis therapy has also been shown to be effective in treatment of some moderately severe UC patients who do not respond to 5-ASA or corticosteroids. ${ }^{34}$ Severe active UC can be treated with intravenous steroids, cyclosporine, or infliximab, which is a form of rescue therapy and acts as a bridge to maintenance therapy with thiopurines or scheduled infliximab therapy. ${ }^{35}$

In addition to pharmacological management, health maintenance is important in patients with UC. ${ }^{36}$ It is recommended that patients get routine vaccinations, such as yearly influenza, pneumococcal every 5 years, tetanus booster every 10 years, complete hepatitis A and B vaccinations, varicella or zoster (contraindicated on biologic therapy), and human papillomavirus for females. Periodic blood test monitoring is also important, depending on the maintenance therapy; moreover, full blood count, liver function, and renal function should be monitored. Annual screening of vitamin D levels should be considered in patients exposed to corticosteroids, and urinalysis should be considered for early screening of nephritis. Patients with long-standing inflammatory disease (pancolitis of 8-10 years and left-sided colitis of over 10 years) should have surveillance colonoscopy every 1 to 2 years once there is no evidence of dysplasia on serial biopsies. Bone mineral density, yearly dermatological examinations (especially on immunomodulators and biologics) as well as a mammogram and pap smears for women should be considered. Patients should also take calcium $1200 \mathrm{~g}$ per day and vitamin D 400-800 IU per day.

\section{Focus on $M M X^{\circledR}$ mesalamine}

Since the mode of action of mesalamine in UC is thought to be a topical effect on the colonic mucosa, all oral mesalamine formulations for UC are designed to deliver 5-ASA to the colon. Unbound 5-ASA ingested orally is rapidly absorbed in the small intestine, so encapsulation in $\mathrm{pH}$-sensitive coatings or with cellulose granules are necessary to prevent premature small bowel absorption of mesalamine. The pharmacology 
of MMX mesalamine is very similar to other mesalamine formulations, and differs only in the duration and timing of colonic release of unbound 5-ASA. MMX ${ }^{\circledR}$ mesalamine technology comprises hydrophilic and lipophilic excipients enclosed in a gastric-resistant, pH-dependent coating. ${ }^{37}$ Eudragit-S (used in Lialda/Mezavant; Shire Pharmaceuticals) is a $\mathrm{pH}$-sensitive polymer that disintegrates at a $\mathrm{pH}>7$, allowing the drug to be released in the terminal ileum or cecum. ${ }^{38}$ The additional lipophilic and hydrophilic matrices within the capsule are designed to allow slower diffusion of the drug through the colon. This delivery system allows a once-daily administration of high-concentration tablets. ${ }^{39}$

\section{Pharmacokinetics}

The results of plasma pharmacokinetics ( $\mathrm{pK}$ ) analyses and mucosal concentrations of delayed-release formulations of 5-ASA have shown high interindividual variability in healthy volunteers and patients with active and inactive UC. ${ }^{40,41}$ Following administration of a single dose of either a delayedrelease or an azo-bonded formulation, only approximately $20 \%$ of the 5-ASA is taken up systemically (assessed by analysis of 5-ASA and its main metabolite, N-acetyl-5-aminosalicylic acid [N-acetyl-5-ASA $]$ in urine). ${ }^{42}$ Mesalamine and its metabolite are also secreted back into the colonic lumen following uptake by the colonic mucosa, reducing further the amount of 5-ASA that will progress to the plasma. ${ }^{43}$ Administration with food delays the first appearance of mesalamine in the plasma by 2 hours compared with administration in the fasted state. ${ }^{44}$ Variations in transit times and $\mathrm{pH}$ conditions in patients with UC could potentially affect how the drug is released and taken up by colonic mucosa. ${ }^{45}$

In a single and multiple dose pharmacokinetic study of Lialda, $2.4 \mathrm{~g}$ or $4.8 \mathrm{~g}$ was administered once daily with standard meals to 28 healthy volunteers per dosage group. ${ }^{44}$ Plasma concentrations of mesalamine were detectable after 4 hours and were maximal by 8 hours after the single dose. Steady state was achieved generally within 2 days after dosing. Mean area under the curve at steady state was only modestly greater (1.1 - to 1.4 -fold) than that predictable from single-dose pharmacokinetics (Table 1). Elimination of absorbed mesalamine is mainly via the renal route following metabolism to N-acetyl-5-ASA. Total (5-ASA and $\mathrm{N}$-acetyl-5-ASA) urinary excretion of oral mesalamine over 24 hours was $21.3 \%{ }^{46}$ In a study comparing Asacol and Lialda, both of which were dosed once daily, both drugs exhibited a similar $\mathrm{pK}$ profile in healthy volunteers. ${ }^{4} \mathrm{~A}$ systematic review of the pharmacokinetic profiles of the different 5-ASA formulations found that systemic 5-ASA absorption
Table I Mean $( \pm S D)$ pK parameters for mesalamine following single dose and steady state administration of MMX mesalamine under fasting or postprandial status

\begin{tabular}{|c|c|c|c|c|c|}
\hline Dosage & $\mathbf{N}$ & $\begin{array}{l}C_{\max } \\
(\mathrm{ng} / \mathrm{mL})\end{array}$ & $\begin{array}{l}\text { Median } \\
\mathbf{T}_{\max } \text { (hours) }\end{array}$ & $\begin{array}{l}A \cup C_{0-\infty} \\
(n g h ~ m L)\end{array}$ & $\begin{array}{l}t_{1 / 2} \\
\text { (hours) }\end{array}$ \\
\hline $2.4 g^{40, a}$ & 48 & $\begin{array}{l}1595 \\
( \pm 1484)\end{array}$ & $12(4-31)$ & $\begin{array}{l}21,084 \\
( \pm 13 \mid 85)\end{array}$ & $\begin{array}{l}7.05 \\
( \pm 5.54)\end{array}$ \\
\hline $4.8 \mathrm{~g}^{40, \mathrm{a}}$ & 48 & $\begin{array}{l}2154 \\
( \pm I \mid 40)\end{array}$ & $12(4-34)$ & $\begin{array}{l}44775 \\
( \pm 30,302)\end{array}$ & $\begin{array}{l}7.25 \\
( \pm 8.32)\end{array}$ \\
\hline $2.4 g^{42, b}$ & 37 & $\begin{array}{l}1553^{c} \\
(857-28 \mid 2)\end{array}$ & & $\begin{array}{l}13,556^{c} \\
(76 \mid 6-24,128)\end{array}$ & $\begin{array}{l}10.2^{c} \\
\left(5.8^{c}-19.9\right)\end{array}$ \\
\hline
\end{tabular}

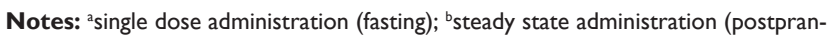
dial); 'square geometric means ( $95 \%$ confidence intervals).

Abbreviations: SD, standard deviation; AUC, area under the plasma concentrationtime curve; $C_{\text {max }}$, maximum plasma concentration; $t_{1 / 2}$, elimination half-life; $T_{\text {max }}$ ' time to $C_{\text {max }}$.

was comparable for the $\mathrm{pH}$-dependent, controlled release, and prodrug formulations. ${ }^{47}$

\section{Pharmacodynamics}

5-ASA is believed to exert a direct effect on the colonic mucosa through a number of different, but not mutually exclusive, anti-inflammatory mechanisms of action. ${ }^{48}$ 5-ASA acts as a synthetic agonist to the peroxisome proliferator-activated receptor- $\gamma$ (PPAR- $\gamma$ ), which is known to be involved in UC inflammation. ${ }^{49}$ It also has been shown to inhibit prostaglandin synthesis (via inhibition of cyclooxygenase), chemotactic leukotriene synthesis (via inhibition of lipoxygenase), ${ }^{50}$ interleukin-1 (IL-1) synthesis, ${ }^{51}$ nuclear factor kappa B (NF- $\mathrm{BB}$ ) activation by tumor necrosis factor (TNF) alpha ${ }^{52}$ and IL-1, ${ }^{53}$ and apoptosis induced by oxidative stress. ${ }^{54}$ No specific studies on the mechanism of action of MMX mesalamine have been published because the anti-inflammatory effects of mesalamine are assumed to be ubiquitous.

\section{Clinical efficacy of MMX mesalamine}

Several randomized placebo-controlled trials have investigated the safety and efficacy of MMX mesalamine compared to placebo. ${ }^{25,26,39,55-59}$ The efficacy of MMX mesalamine in inducing remission in active UC was demonstrated in two randomized, double-blind placebo-controlled trials ${ }^{39,55}$ (Table 2). Kamm et al randomized 343 patients with active mild-moderate UC to receive Lialda ( $2.4 \mathrm{~g} /$ day or $4.8 \mathrm{~g} /$ day), Asacol (2.4 g/day), or placebo. ${ }^{39}$ After 8 weeks, $40.5 \%$ of the $2.4 \mathrm{~g} /$ day $(P=0.01)$ and $41.2 \%$ of the $4.8 \mathrm{~g} /$ day $(P=0.007)$ achieved clinical and endoscopic remission, compared to $22.1 \%$ in the placebo arm. No comparative statistical analyses between the Asacol and MMX mesalamine group were reported. They also showed that MMX mesalamine 
Table 2 Clinical efficacy of MMX mesalamine (MES) in induction (8 weeks) of remission in patients with mild to moderate ulcerative colitis

\begin{tabular}{|c|c|c|c|c|}
\hline Study & $\mathbf{N}$ & Doses & $\begin{array}{l}\text { Clinical and endoscopic } \\
\text { remission (\%) (OR, } 95 \% \mathrm{Cl})\end{array}$ & $\begin{array}{l}\text { Failure } \\
\text { rates (\%) }\end{array}$ \\
\hline \multirow[t]{4}{*}{ Kamm et $\mathrm{a}^{39}$} & 84 & MMX mesalamine $2.4 \mathrm{~g}$ daily & $40.5^{* *}(2.40 ; 1.23-4.69)$ & $21.4 * * *$ \\
\hline & 85 & MMX mesalamine $4.8 \mathrm{~g}$ daily & $41.2 * *(2.47 ; 1.15-5.30)$ & $20.0 * * *$ \\
\hline & 86 & Asacol $^{2} 800 \mathrm{mg}$ three times daily & $32.6(1.70 ; 0.86-3.36)$ & $27.9 * *$ \\
\hline & 86 & Placebo & 22.1 & 47.7 \\
\hline \multirow[t]{3}{*}{ Lichtenstein et $\mathrm{a}^{56}$} & 88 & MMX mesalamine $1.2 \mathrm{~g}$ twice daily & $34.1 * * *(3.48 ; 1.44-8.4 I)$ & $28.4 * * *$ \\
\hline & 85 & MES $4.8 \mathrm{~g}$ daily & $29.2 * *(2.78 ; 1.27-6.06)$ & $24.7^{* * *}$ \\
\hline & 89 & Placebo & 12.9 & 54.1 \\
\hline \multirow[t]{2}{*}{ Kamm et $\mathrm{al}^{58, \mathrm{~b}}$} & 197 & $\begin{array}{l}\text { MMX mesalamine } 2.4 \mathrm{~g} \text { twice daily } \\
\text { (No response to MMX mesalamine previously) }\end{array}$ & 59.5 & - \\
\hline & 107 & $\begin{array}{l}\text { MMX mesalamine } 2.4 \mathrm{~g} \text { twice daily } \\
\text { (Placebo previously) }\end{array}$ & 57 & - \\
\hline
\end{tabular}

Notes: $* P<0.05$; $* * P<0.01$; $* * * P<0.001$ vs placebo. alncluded as an internal reference arm; no comparative statistical analyses with the mesalamine treatment arms were reported; ${ }^{b}$ patients who did not achieve the primary endpoint of clinical and endoscopic remission in the 8 -week Phase III trials ${ }^{35,51}$ were eligible for enrolment in the noncomparative extension study ( $4.8 \mathrm{~g} \mathrm{MMX} \mathrm{mesalamine} \mathrm{for} 8$ weeks) ${ }^{54}$

Abbreviation: OR, odds ratio.

at a higher dose (4.8 g once daily) was associated with endoscopic improvement compared to placebo ( $77 \%$ vs $41 \%$ ), MMX mesalamine at a dose of $2.4 \mathrm{~g}$ once daily, and delayed release mesalamine was not statistically significant compared to placebo. However both low and high doses of MMX mesalamine were associated with improved induction of endoscopic remission (69\% and $76 \%)$ compared to placebo (46\%). Similarly, Lichtenstein et al showed that MMX mesalamine ( $2.4 \mathrm{~g} /$ day or $4.8 \mathrm{~g}$ /day) was superior to placebo in inducing remission in patients with mild-tomoderate UC..$^{55}$ There was no significant difference in terms of the clinical and endoscopic remission rate between the MMX mesalamine $1.2 \mathrm{~g}$ twice daily and $4.8 \mathrm{~g}$ once daily groups (odds ratio [OR], 1.25; 95\% CI: 0.66-2.36). Median time to achieve initial clinical remission was significantly shorter in the MMX mesalamine $1.2 \mathrm{~g}$ twice daily (43 days) or $4.8 \mathrm{~g}$ once daily (44 days) groups than in the placebo group (which was not achieved) ${ }^{55}$ Both studies excluded patients with ulcerative proctitis (inflammation to $>15 \mathrm{~cm}$ from the anus).

In a pooled analysis of the above studies, MMX mesalamine was found effective in active UC regardless of disease extent, disease severity, sex, and previous low-dose 5-ASA therapy. ${ }^{56}$ In an induction extension study by Kamm et al, patients who did not achieve the primary endpoint of clinical and endoscopic remission in the 8-week Phase III trials $(n=304)$ were eligible for enrolment in the noncomparative extension study in which all patients received MMX mesalamine $4.8 \mathrm{~g}$ /day, given as $2.4 \mathrm{~g}$ twice daily for 8 weeks. ${ }^{58}$ This extension treatment was effective in inducing remission in $59.5 \%$ of patients previously not in remission.
Remission rates were similar irrespective of prior treatment in the acute Phase III studies (MMX 2.4 g/day, MMX 4.8 g/day, Asacol $0.8 \mathrm{~g} /$ day, or placebo). ${ }^{58}$

\section{Maintenance of remission}

The efficacy of MMX mesalamine as maintenance therapy in UC has been assessed in two 12-month, randomized, double-blind ${ }^{25}$ or open-label, ${ }^{59}$ multicenter Phase III trials and a 12-month noncomparative, multicenter Phase IV trial ${ }^{26}$ (Table 3). The efficacy of MMX mesalamine was shown in a trial in which patients in clinical and endoscopic remission (after being treated with MMX mesalamine) were randomly assigned to MMX mesalamine $1.2 \mathrm{~g}$ twice daily or $2.4 \mathrm{~g}$ every day ${ }^{59}$ At 1 year, the two regimens were associated with a similar rate of clinical and endoscopic remission (64\% vs 69\%). A study comparing Lialda $2.4 \mathrm{~g}$ daily and Asacol $2.4 \mathrm{~g}$ daily found no significant difference between the two drugs in maintaining clinical remission (68\% and $65.9 \%$, respectively). ${ }^{25}$ Kane et al showed that MMX mesalamine $2.4 \mathrm{~g} /$ day, maintained disease quiescence in $76.5 \%$ of patients at 6 months (primary endpoint) and $64.4 \%$ at 12 months. ${ }^{26}$ As a secondary analysis, clinical recurrence was observed in $20.6 \%$ of patients who were $\geq 80 \%$ adherent and $36.1 \%$ of patients with $<80 \%$ adherence $(P=0.05)$.

Data on studies of MMX mesalamine in endoscopic maintenance of remission is sparse. In the maintenance of remission studies by Kamm et a ${ }^{59}$ and Prantera et al, ${ }^{25}$ no major difference was noted between once daily and twice daily dosing of MMX mesalamine or between MMX mesalamine and a delayed release mesalamine. A recent study by D'Haens et al showed that once daily dosing of MMX mesalamine at $2.4 \mathrm{~g}$ 
Table 3 Clinical efficacy of MMX mesalamine in maintenance of remission ( 12 months) in patients with mild to moderate ulcerative colitis

\begin{tabular}{lllll}
\hline Study & N & Doses & $\begin{array}{l}\text { Clinical and endoscopic } \\
\text { remission (\%) }\end{array}$ & $\begin{array}{l}\text { Relapse rates } \\
\text { at I 2 months (\%) }\end{array}$ \\
\hline Kamm et al $^{59}$ & 232 & MMX mesalamine I.2 g twice daily & 68.5 & 6.8 \\
& 219 & MMX mesalamine 2.4 g twice daily & 64.4 & 11.1 \\
Prantera et al ${ }^{25}$ & 162 & MMX mesalamine 2.4 g once daily & $60.9^{\mathrm{a}}$ & 15.0 \\
& 156 & Asacol 2.4 g once daily & $61.7^{\mathrm{a}}$ & 29.9 \\
Kane et al $^{26}$ & 167 & MMX mesalamine 2.4 g once daily & - & $35.6^{\mathrm{a}}$ \\
\hline
\end{tabular}

Note: aPrimary endpoint.

was not inferior to twice daily dosing with delayed release mesalamine at $1.6 \mathrm{~g}$ /day for maintenance of endoscopic remission in patients with UC $(83.7 \%$ vs $81.5 \%){ }^{60}$

\section{Safety of MMX mesalamine}

Newer 5-ASA preparations, such as MMX mesalamine, were intended to avoid the adverse effects of sulfasalazine while maintaining its therapeutic benefits. As class of drug, mesalamine has been shown to have an excellent safety profile and is well tolerated by patients. ${ }^{61}$ Examples of the unwanted effects of mesalamine reported include nausea, vomiting, dyspepsia, malaise, headache, abdominal pain, and rash. ${ }^{61}$ A paradoxical worsening of diarrhea has been attributed to mesalamine, especially early in therapy. ${ }^{62}$ Less common adverse effects include blood dyscrasias, pancreatitis, oligospermia (which is reversible upon discontinuation of the drug), drug-induced liver injury (DILI), and nephrotoxicity. ${ }^{63-65}$ To compare the short-term adverse events among the 5-ASA agents (mesalamine, olsalazine, and balsalazide), Loftus et al performed a meta-analysis of 46 randomized trials for mild-to-moderate UC. ${ }^{6}{ }^{6}$ The study concluded that all three 5-ASA formulations produced similar adverse effects in the short term. Patients on mesalamine experience fewer adverse events or withdrawals due to serious side effects compared to those on sulfasalazine. The majority of treatment-emergent adverse events were mild to moderate in severity and most commonly gastrointestinal in nature. ${ }^{66}$

Renal damage occurring due to 5-ASA-based treatment of inflammatory bowel disease also appears to be rare. Adverse reactions consist of hypersensitivity reactions and, in the case of mesalamine, chronic interstitial nephritis. Fifty percent of reported cases of mesalamine-induced interstitial nephritis present within 1 year of treatment initiation, but the reported time range for presentation is wide at 3 months to 5 years. ${ }^{67}$ The review of reported cases by World et al showed that $85 \%$ of cases of interstitial nephritis detected within 10 months of mesalamine therapy initiation responded completely to drug withdrawal with restoration of normal renal function. ${ }^{67}$ Unfortunately, interstitial nephritis is difficult to detect early by urinalysis, and currently there are no screening methods other than monitoring serum creatinine. Regular monitoring of renal function is recommended in patients receiving MMX mesalamine. ${ }^{36}$

Because mesalamine inhibits thiopurine methyltransferase, which metabolizes thiopurine-containing drugs, there is an increased potential for blood disorders when mesalamine is taken with concomitant azathioprine or mercaptopurine ${ }^{68}$ Mesalamine may decrease anticoagulant activity when coadministered with coumarin-type anticoagulants (eg, warfarin), and close monitoring of the prothrombin time is recommended. ${ }^{69}$

MMX mesalamine specifically is generally well tolerated, with no clinically significant differences in tolerability compared with placebo ${ }^{39,55}$ or Asacol. ${ }^{25,39}$ No dose-dependent relationship to adverse events was noted between MMX mesalamine dosage groups in the 8 -week induction trials. ${ }^{39,55}$ Treatment-related adverse events were reported in 14.1\% of MMX mesalamine $2.4 \mathrm{~g} /$ day recipients, $14.5 \%$ of MMX mesalamine $4.8 \mathrm{~g}$ /day recipients, and $14.0 \%$ of placebo recipients in the two 8 -week Phase III trials, ${ }^{57}$ in $8.0 \%$ of MMX mesalamine $2.4 \mathrm{~g} /$ day recipients, $9.5 \%$ of Asacol $2.4 \mathrm{~g} /$ day recipients in the 12-month European trial, ${ }^{25}$ and in $11.5 \%$ of MMX mesalamine recipients as reported in a Phase IV study published recently. ${ }^{26}$

Limited data are available on the use of MMX mesalamine in pregnant patients. A meta-analysis of the use of mesalamine or mesalamine-containing drugs in pregnant women with IBD did not show a statistically significant difference compared with no medication in the incidence of congenital malformations, stillbirth, spontaneous abortion, preterm delivery, or low birth weight. ${ }^{70}$ However, MMX mesalamine should only be used in pregnant patients if the benefits clearly outweigh the risks. ${ }^{44}$

\section{MMX mesalamine in clinical practice Quality of life}

Past studies with UC patients indicated that disease activity strongly predicts health-related quality of life (HRQoL). ${ }^{71,72}$ 
The first study to assess MMX mesalamine in changes to disease specific HRQoL reported that following 8 weeks of treatment with MMX mesalamine 2.4-4.8 g/day, patients with active mild-to-moderate UC showed significant improvement in all aspects of disease-specific HRQoL measured by the Short Inflammatory Bowel Disease Questionnaire (SIBDQ). ${ }^{73}$ This quality-of-life level was maintained by quiescent UC patients in the course of year-long continuous once-daily MMX mesalamine $2.4 \mathrm{~g} /$ day treatment. ${ }^{73}$ The improvements in HRQoL corresponded to improvements in disease activity in the active group more so than the quiescent group.

\section{Adherence}

Up to $40 \%$ of patients with UC fail to comply with 5-ASA therapy. ${ }^{74,75}$ In patients who received non-MMX or MMX formulations of mesalamine, nonadherence to treatment was associated with a higher likelihood of disease recurrence, a higher financial cost of health care management, and a reduced level of protection against the development of CRC than adherence to treatment. ${ }^{26,76-78}$ A variety of barriers to adherence have been reported by patients, including lifestyle, risk of side effects, and financial factors. ${ }^{79,80}$ A once-daily dose of mesalamine has been shown as effective as twice daily, with improved patient compliance in those with reduced pill burden. ${ }^{81}$ However, a meta-analysis by Ford et al comparing once-daily dosing with mesalamine with conventional dosing schedules showed no significant benefit of once daily over multiple doses in risk of nonadherence (relative risk [RR], 0.87; 95\% CI: $0.46-1.66) .{ }^{20}$ Although compliance was $>85 \%$ in all three 12-month maintenance trials, ${ }^{25,26,58}$ the impact of once-daily dosing on long-term treatment adherence in the community remains to be seen. Patients receiving once-daily MMX mesalamine had significantly higher persistency after 1 year of treatment than patients receiving other oral 5-ASA therapies, based on pharmacy refills. ${ }^{82}$

\section{Drug costs}

The wholesale cost of MMX mesalamine is US\$726 for a pack of 120 tablets. ${ }^{83}$ The cost-effectiveness of MMX mesalamine relative to Asacol as remission induction and maintenance therapy in adult patients with mild-to-moderate UC was performed from a UK health care payer's perspective. It concluded that MMX mesalamine was associated with an incremental cost per patient but with significant increase in remission times, fewer hospitalizations, and fewer surgical events per patient. ${ }^{84}$ Further comparative cost-effective studies of mesalamine agents and doses are required to confirm this finding in other settings.

\section{Chemoprophylaxis of CRC}

The cumulative life time risk of developing CRC in patients with UC has been reported in historical cohorts to be as high as $10 \%-20 \% .^{85}$ More recent population-based data have shown that the risk of CRC is actually closer to $1.3 \%-1.6 \%$ after $14-15$ years in IBD patients. ${ }^{86,87} \mathrm{~A}$ meta-analysis by Jess et al showed that in CRC, risk was higher in UC patients with a pooled SIR of $2.4(95 \% \mathrm{CI}: 2.1-2.7) .{ }^{88}$ Male sex, young age of diagnosis, and extensive colitis were particular risk factors. Case control studies of patients with colon cancer and UC have reported conflicting data on the impact of 5-ASA on the risk of CRC. ${ }^{89-91}$ A prospective RCT of 5-ASA in prevention of polyps in adults with a history of polyps did not show a chemoprotective effect of 5-ASA. ${ }^{92}$ A meta-analysis of nine observational studies involving 1932 patients reported a protective association between 5-ASA use and CRC (OR, 0.51; 95\% CI: 0.37-0.69) or a combined endpoint of CRC and dysplasia (OR 0.51; 95\% CI: 0.38-0.69), which equates to a $49 \%$ reduction in the risk of CRC or CRC/dysplasia with regular 5-ASA use. ${ }^{93}$ The reduced risk was maintained by regular use of at least $1.2 \mathrm{~g}$ of mesalamine daily. Compliance with prescribed 5-ASA therapy can influence the risk of CRC. A nested case-control study involving 18,969 patients with IBD in the UK General Practice Research Database (1987-2001) showed that regular 5-ASA users (defined as six prescriptions in the previous 12 months) had a significantly reduced risk of $\mathrm{CRC}$ compared with irregular 5-ASA users (adjusted OR, 0.60; 95\% CI: $0.38-0.96) .{ }^{76}$ No specific published studies have examined the role of MMX mesalamine in CRC prophylaxis.

A recent publication suggested that the overall risk of CRC among patients with UC was comparable to that of the general population (RR, 1.07; 95\% CI: 0.95-1.21) and that the risk for $\mathrm{CRC}$ in UC patients is on a decline. ${ }^{87}$ For patients with UC, the overall RR for CRC decreased from 1.34 (95\% CI: $1.13-1.58)$ in 1987 to 1988 to 0.57 (95\% CI: 0.41-0.80) in 1999 to 2008. The declining risk for CRC from 1979 to 2008 might result from improved therapies for patients with IBD.

\section{Conclusion}

Mesalamine is an effective first-line agent for the induction and maintenance of remission in patients with mild-tomoderate UC when administered orally, rectally, or both. For patients with more severe disease, other agents such as steroids or infliximab are required. There may be additional benefits from mesalamine in chemoprophylaxis against colon cancer, but there is conflicting data on this subject. 
Adherence to treatment schedules with mesalamine remains an issue in practice. MMX mesalamine provides a higher per-pill dose of mesalamine than other mesalamine formulations, allowing for once-daily dosing. The reduced pill burden may improve patient adherence in clinical practice, although this will require further study to confirm. Its efficacy and safety profile is similar to other mesalamine formulations. As the patent for the pioneer mesalamine formulation (Asacol; Warner Chilcott Company, Dublin, Ireland) approaches patent expiry (July, 2013), it is unclear how the arrival of generic mesalamine formulations will affect MMX mesalamine's share of the US market and whether third-party payers (insurers and governments) will tier access to MMX mesalamine in the face of cheaper mesalamine options.

\section{Disclosure}

The authors report no conflicts of interest in this work. KSN has received research funding from Merck Sharp \& Dohme Ireland. ACM has received research funding from Salix, Shire Pharmaceuticals, Procter and Gamble. ACM is supported by National Institutes of Health grant K23DK084338.

\section{References}

1. Loftus CG, Loftus Jr EV, Harmsen WS, et al. Update on the incidence and prevalence of Crohn's disease and ulcerative colitis in Olmsted County, Minnesota, 1940-2000. Inflamm Bowel Dis. 2007;13(3): 254-261.

2. Danese S, Fiocchi C. Ulcerative colitis. N Engl J Med. 2011;365(18): 1713-1725.

3. Kornbluth A, Sachar DB. Ulcerative colitis practice guidelines in adults: American College of Gastroenterology, Practice Parameters Committee. Am J Gastroenterol. 2010;105(3):501-523.

4. Ricart E, Panaccione R, Loftus Jr EV, et al. Autoimmune disorders and extraintestinal manifestations in first-degree familial and sporadic inflammatory bowel disease: a case-control study. Inflamm Bowel Dis. 2004;10(3):207-214.

5. Ekbom A, Helmick C, Zack M, Adami HO. Ulcerative colitis and colorectal cancer. N Engl J Med. 1990;323(18):1228-1233.

6. Eaden J, Abrams K, Mayberry J. The risk of colorectal cancer in ulcerative colitis: a meta-analysis. Gut. 2001;48(4):526-535.

7. Roth M, Petersen G, McElree C, Feldman E, Rotter J. Geographic origins of Jewish patients with inflammatory bowel disease. Gastroenterology. 1989;97(4):900-904.

8. Loftus EV. Clinical epidemiology of inflammatory bowel disease: incidence, prevalence, and environmental influences. Gastroenterology. 2004;126(6):1504-1517.

9. Kappelman MD, Rifas-Shiman SL, Kleinman K, et al. The prevalence and geographic distribution of Crohn's disease and ulcerative colitis in the United States. Clin Gastroenterol Hepatol. 2007;5(12):1424-1429.

10. Cosnes J, Gower-Rousseau C, Seksik P, Cortot A. epidemiology and natural history of inflammatory bowel diseases. Gastroenterology. 2011;140(6):1785-1794.e1784.

11. Halfvarson J, Bodin L, Tysk C, Lindberg E, Järnerot G. Inflammatory bowel disease in a Swedish twin cohort: a long-term follow-up of concordance and clinical characteristics. Gastroenterology. 2003; 124(7):1767-1773.

12. Burger D, Travis S. Conventional medical management of inflammatory bowel disease. Gastroenterology. 2011;140(6):1827-1837.
13. Cohen RD, Woseth DM, Thisted RA, Hanauer SB. A meta-analysis and overview of the literature on treatment options for left-sided ulcerative colitis and ulcerative proctitis. Am J Gastroenterol. 2000;95(5): $1263-1276$.

14. Harris M, Lichtenstein G. Delivery and efficacy of topical 5-aminosalicylic acid (mesalamine) therapy in the treatment of ulcerative colitis. Aliment Pharmacol Ther. 2011;33(9):996-1009.

15. Marshall J, Irvine E. Rectal aminosalicylate therapy for distal ulcerative colitis: a meta-analysis. Aliment Pharmacol Ther. 1995;9(3): 293-300.

16. Ford AC, Khan KJ, Achkar J-P, Moayyedi P. Efficacy of oral vs topical, or combined oral and topical 5-aminosalicylates, in ulcerative colitis: systematic review and meta-analysis. Am J Gastroenterol. 2012;107(2): 167-176.

17. Ford AC, Khan KJ, Sandborn WJ, Hanauer SB, Moayyedi P. Efficacy of topical 5-aminosalicylates in preventing relapse of quiescent ulcerative colitis: a meta-analysis. Clin Gastroenterol Hepatol. 2012;10(5): 513-519.

18. Sutherland L, Macdonald J. Oral 5-aminosalicylic acid for induction of remission in ulcerative colitis. Cochrane Database Syst Rev. 2006;2: CD000543.

19. Sutherland L, Roth D, Beck P, May G, Makiyama K. Oral 5-aminosalicylic acid for maintenance of remission in ulcerative colitis. Cochrane Database Syst Rev. 2006;2:CD000544.

20. Ford AC, Achkar JP, Khan KJ, et al. Efficacy of 5-aminosalicylates in ulcerative colitis: systematic review and meta-analysis. Am J Gastroenterol. 2011;106(4):601-616.

21. Ito H, Iida M, Matsumoto T, et al. Direct comparison of two different mesalamine formulations for the induction of remission in patients with ulcerative colitis: a double-blind, randomized study. Inflamm Bowel Dis. 2010;16(9):1567-1574.

22. Ford AC, Khan KJ, Sandborn WJ, Kane SV, Moayyedi P. Once-daily dosing vs conventional dosing schedule of mesalamine and relapse of quiescent ulcerative colitis: systematic review and meta-analysis. $\mathrm{Am}$ J Gastroenterol. 2011;106(12):2070-2077.

23. Bernard F, Herve H, Gilbert T, et al. Once-daily versus twice-daily mesalazine for active ulcerative colitis: efficacy results from MOTUS, a multicentre, controlled, randomised, investigator-blinded study. Gastroenterology. 2012;142(5 Suppl 1):S-197.

24. Pierik MJ, Flourie B, Hagege H, et al. Once-daily versus twicedaily mesalazine for mild to moderately active ulcerative colitis: mucosal healing and early response data from motus, a multicentre, controlled, randomised, investigator-blinded study. Gastroenterology. 2012;142(5 Suppl 1):S-198.

25. Prantera C, Kohn A, Campieri M, et al. Clinical trial: ulcerative colitis maintenance treatment with 5-ASA: a 1-year, randomized multicentre study comparing $\mathrm{MMX}^{\circledR}$ with Asacol ${ }^{\circledR}$. Aliment Pharmacol Ther. 2009;30(9):908-918.

26. Kane S, Katz S, Jamal MM, et al. Strategies in maintenance for patients receiving long-term therapy (SIMPLE): A study of MMX mesalamine for the long-term maintenance of quiescent ulcerative colitis. Inflamm Bowel Dis. 2012;18(6):1026-1033.

27. Orchard TR, van der Geest SAP, Travis SPL. Randomised clinical trial: early assessment after 2 weeks of high-dose mesalazine for moderately active ulcerative colitis - new light on a familiar question. Aliment Pharmacol Ther. 2011;33(9):1028-1035.

28. Lichtenstein GR, Rutgeerts P. Importance of mucosal healing in ulcerative colitis. Inflamm Bowel Dis. 2010;16(2):338-346.

29. Lichtenstein G, Ramsey D, Rubin D. Randomised clinical trial: delayedrelease oral mesalazine $4.8 \mathrm{~g}$ /day vs $2.4 \mathrm{~g} /$ day in endoscopic mucosal healing-ASCEND I and II combined analysis. Aliment Pharmacol Ther. 2011;33(6):672-678.

30. Sandborn WJ, Hanauer S, Lichtenstein GR, Safdi M, Edeline M, Scott Harris M. Early symptomatic response and mucosal healing with mesalazine rectal suspension therapy in active distal ulcerative colitis additional results from two controlled studies. Aliment Pharmacol Ther. 2011;34(7):747-756. 
31. Lichtenstein GR, Abreu MT, Cohen R, Tremaine W. American Gastroenterological Association Institute technical review on corticosteroids, immunomodulators, and infliximab in inflammatory bowel disease. Gastroenterology. 2006;130(3):940-987.

32. Carbonnel F. Methotrexate: a drug of the future in ulcerative colitis? Curr Drug Targets. 2011;12(10):1413-1416.

33. Rutgeerts P, Sandborn WJ, Feagan BG, et al. Infliximab for induction and maintenance therapy for ulcerative colitis. $N$ Engl J Med. 2005; 353(23):2462-2476.

34. Yamamoto T, Umegae S, Matsumoto K. Mucosal healing in patients with ulcerative colitis during a course of selective leukocytapheresis therapy: a prospective cohort study. Inflamm Bowel Dis. 2010;16(11):1905-1911.

35. Moss AC, Peppercorn MA. Steroid-refractory severe ulcerative colitis: what are the available treatment options? Drugs. 2008;68(9): 1157-1167.

36. Moscandrew M, Mahadevan U, Kane S. General health maintenance in IBD. Inflamm Bowel Dis. 2009;15(9):1399-1409.

37. Fiorino G, Fries W, De La Rue S, Malesci A, Repici A, Danese S. New drug delivery systems in inflammatory bowel disease: MMX and tailored delivery to the gut. Curr Med Chem. 2010;17(17):1851-1857.

38. Fernandez-Becker NQ, Moss AC. Improving delivery of aminosalicylates in ulcerative colitis: effect on patient outcomes. Drugs. 2008;68(8): 1089-1103.

39. Kamm MA, Sandborn WJ, Gassull M, et al. Once-daily, high-concentration MMX mesalamine in active ulcerative colitis. Gastroenterology. 2007; 132(1):66-75.

40. Hussain F, Ajjan R, Kapur K, Moustafa M, Riley S. Once versus divided daily dosing with delayed-release mesalazine: a study of tissue drug concentrations and standard pharmacokinetic parameters. Aliment Pharmacol Ther. 2001;15(1):53-62.

41. De Vos M, Verdievel H, Schoonjans R, Praet M, Bogaert M, Barbier F. Concentrations of 5-ASA and Ac-5-ASA in human ileocolonic biopsy homogenates after oral 5-ASA preparations. Gut. 1992;33(10): 1338-1342.

42. Sandborn W, Hanauer S, Buch A. Comparative pharmacokinetics of equimolar doses of 5-aminosalicylate administered as oral mesalamine (Asacol) and balsalazide: a randomized, single-dose, crossover study in healthy volunteers. Aliment Pharmacol Ther. 2004;19(10): 1089-1098.

43. Klotz U. Clinical pharmacokinetics of sulphasalazine, its metabolites and other prodrugs of 5-aminosalicylic acid. Clin Pharmacokinet. 1985;10(4):285-302.

44. Shire US Inc. Lialda (mesalamine) delayed release tablets: US prescribing information [online]. Available from: http://www.accessdata fda.gov/drugsatfda_docs/label/2010/022000s0031bl.pdf. Accessed March 23, 2012.

45. Akiho H, Ihara E, Motomura Y, Nakamura K. Cytokine-induced alterations of gastrointestinal motility in gastrointestinal disorders. World J Gastrointest Pathophysiol. 2011;2(5):72-81.

46. Sandborn W, Balan G, Kuzmak B, Hanauer S. Comparable pharmacokinetics of two delayed release formulations of oral mesalamine. Am J Gastroenterol. 2007;102:S465.

47. Sandborn W, Hanauer S. The pharmacokinetic profiles of oral mesalazine formulations and mesalazine pro-drugs used in the management of ulcerative colitis. Aliment Pharmacol Ther. 2003;17(1):29-42.

48. Desreumaux P, Ghosh S. Review article: mode of action and delivery of 5-aminosalicylic acid-new evidence. Aliment Pharmacol Ther. 2006; 24(Suppl 1):2-9.

49. Dubuquoy L, Rousseaux C, Thuru X, et al. PPAR- $\gamma$ as a new therapeutic target in inflammatory bowel diseases. Gut. September 1, 2006; 55(9):1341-1349.

50. Stenson W, Lobos E. Sulfasalazine inhibits the synthesis of chemotactic lipids by neutrophils. J Clin Invest. 1982;69(2):494-497.

51. Mahida Y, Lamming C, Gallagher A, Hawthorne A, Hawkey C. 5-Aminosalicylic acid is a potent inhibitor of interleukin 1 beta production in organ culture of colonic biopsy specimens from patients with inflammatory bowel disease. Gut. 1991;32(1):50-54.
52. Kaiser GC, Yan F, Polk DB. Mesalamine blocks tumor necrosis factor growth inhibition and nuclear factor [kappa] B activation in mouse colonocytes. Gastroenterology. 1999;116(3):602-609.

53. Egan LJ, Mays DC, Huntoon CJ, et al. Inhibition of interleukin-1stimulated NF- $\kappa$ B RelA/p65 phosphorylation by mesalamine is accompanied by decreased transcriptional activity. J Biol Chem. 1999;274(37): 26448-26453.

54. Sandoval M, Liu X, Mannick E, Clark D, Miller M. Peroxynitriteinduced apoptosis in human intestinal epithelial cells is attenuated by mesalamine. Gastroenterology. 1997;113(5):1480-1488.

55. Lichtenstein GR, Kamm MA, Boddu P, et al. Effect of once-or twice-daily MMX mesalamine (SPD476) for the induction of remission of mild to moderately active ulcerative colitis. Clin Gastroenterol Hepatol. 2007;5(1):95-102.

56. Lichtenstein G, Kamm M, Sandborn W, Lyne A, Joseph R. MMX mesalazine for the induction of remission of mild-to-moderately active ulcerative colitis: efficacy and tolerability in specific patient subpopulations. Aliment Pharmacol Ther. 2008;27(11):1094-1102.

57. Sandborn WJ, Kamm MA, Lichtenstein GR, Lyne A, ButlerT, Joseph RE. MMX Multi Matrix System ${ }^{\circledR}$ mesalazine for the induction of remission in patients with mild-to-moderate ulcerative colitis: a combined analysis of two randomized, double-blind, placebo-controlled trials. Aliment Pharmacol Ther. 2007;26(2):205-215.

58. Kamm MA, Lichtenstein GR, Sandborn WJ, et al. Effect of extended MMX mesalamine therapy for acute, mild-to-moderate ulcerative colitis. Inflamm Bowel Dis. 2009;15(1):1-8.

59. Kamm MA, Lichtenstein GR, Sandborn WJ, et al. Randomised trial of once-or twice-daily MMX mesalazine for maintenance of remission in ulcerative colitis. Gut. 2008;57(7):893-902.

60. D’Haens G, Sandborn WJ, Barrett K, et al. Once-daily MMX ${ }^{\circledR}$ mesalamine for endoscopic maintenance of remission of ulcerative colitis. Am J Gastroenterol. May 8, 2012. [Epub ahead of print.]

61. Moss A, Peppercorn M. The risks and the benefits of mesalazine as a treatment for ulcerative colitis. Expert Opin Drug Saf. 2007;6(2):99-107.

62. Gupta MK, Pollack S, Hutchings JJ. Mesalamine induced symptom exacerbation of ulcerative colitis: Case report and brief discussion. World J Gastrointest Pharmacol Ther. 2010;1(6):132-134.

63. Ransford R, Langman M. Sulphasalazine and mesalazine: serious adverse reactions re-evaluated on the basis of suspected adverse reaction reports to the Committee on Safety of Medicines. Gut. 2002;51(4): 536-539.

64. Gisbert JP, González-Lama Y, Maté J. 5-Aminosalicylates and renal function in inflammatory bowel disease: A systematic review. Inflamm Bowel Dis. 2007;13(5):629-638.

65. Pitchumoni C, Rubin A, Das K. Pancreatitis in inflammatory bowel diseases. J Clin Gastroenterol. 2010;44(4):246-253.

66. Loftus Jr E, Kane S, Bjorkman D. Short-term adverse effects of 5 -aminosalicylic acid agents in the treatment of ulcerative colitis. Aliment Pharmacol Ther. 2004;19(2):179-189.

67. World MJ, Stevens PE, Ashton MA, Rainford DJ. Mesalazine-associated interstitial nephritis. Nephro Dial Transplant. 1996;11(4):614-621.

68. Lowry P, Franklin C, Weaver A, et al. Leucopenia resulting from a drug interaction between azathioprine or 6-mercaptopurine and mesalamine, sulphasalazine, or balsalazide. Gut. 2001;49(5):656-664.

69. Marinella M. Mesalamine and warfarin therapy resulting in decreased warfarin effect. Ann Pharmacother. 1998;32(7):841-842.

70. Rahimi R, Nikfar S, Rezaie A, Abdollahi M. Pregnancy outcome in women with inflammatory bowel disease following exposure to 5-aminosalicylic acid drugs: A meta-analysis. Reprod Toxicol. 2008;25(2):271-275.

71. Janke KH, Klump B, Gregor M, Meisner C, Haeuser W. Determinants of life satisfaction in inflammatory bowel disease. Inflamm Bowel Dis. 2005;11(3):272-286.

72. Hoivik ML, Moum B, Solberg IC, et al. Health-related quality of life in patients with ulcerative colitis after a 10-year disease course: results from the IBSEN study. Inflamm Bowel Dis. September 20, 2011. [Epub ahead of print.] 
73. Solomon D, Yarlas A, Hodgkins P, Karlstadt R, Yen L, Kane S. The impact of MMX mesalazine on disease-specific health-related quality of life in ulcerative colitis patients. Aliment Pharmacol Ther. 2012;35(12):1365-2036.

74. Kane SV, Cohen RD, Aikens JE, Hanauer SB. Prevalence of nonadherence with maintenance mesalamine in quiescent ulcerative colitis. $\mathrm{Am}$ J Gastroenterol. 2001;96(10):2929-2933.

75. Moshkovska T, Stone M, Clatworthy J, et al. An investigation of medication adherence to 5-aminosalicylic acid therapy in patients with ulcerative colitis, using self-report and urinary drug excretion measurements. Aliment Pharmacol Ther. 2009;30(11-12):1118-1127.

76. van Staa TP, Card T, Logan R, Leufkens H. 5-Aminosalicylate use and colorectal cancer risk in inflammatory bowel disease: a large epidemiological study. Gut. 2005;54(11):1573-1578.

77. Kane S, Shaya F. Medication non-adherence is associated with increased medical health care costs. Dig Dis Sci. 2008;53(4):1020-1024.

78. Higgins PDR, Rubin D, Kaulback K, Schoenfield P, Kane S. Systematic review: impact of non-adherence to 5-aminosalicylic acid products on the frequency and cost of ulcerative colitis flares. Aliment Pharmacol Ther. 2009;29(3):247-257.

79. Bernick SJ, Kane S. Insight into the widespread problem of nonadherence to therapy in ulcerative colitis patients. Expert Rev Clin Immunol. 2010;6(4):677-682.

80. Moss AC BK, Ahmed A, Cheifetz AS, Devien J, Yen L. Factors influencing adherence to mesalamine in patients with inflammatory bowel disease: a patient reported qualitative analysis. Am J Gastroenterol. 2011;106(S2):S442.

81. Sandborn WJ, Korzenik J, Lashner B, et al. Once-daily dosing of delayed-release oral mesalamine (400 $\mathrm{mg}$ tablet) is as effective as twice-daily dosing for maintenance of remission of ulcerative colitis. Gastroenterology. 2010;138(4):1286-1296.

82. Kane S, Sumner M, Solomon D, Jenkins M. Twelve-month persistency with oral 5-aminosalicylic acid therapy for ulcerative colitis: results from a large pharmacy prescriptions database. Dig Dis Sci. 2011;56(12): 3463-3470.
83. American Hospital Formulary Service Pharmacologic-Therapeutic Classification. 2010. Available from: http://www.ashp.org/ahfs. Accessed May 2012.

84. Brereton N, Bodger K, Kamm MA, Hodgkins P, Yan S, Akehurst R. A cost-effectiveness analysis of MMX mesalazine compared with mesalazine in the treatment of mild-to-moderate ulcerative colitis from a UK perspective. J Med Econ. 2010;13(1):148-161.

85. Jess T, Loftus EV, Velayos FS, et al. Risk of intestinal cancer in inflammatory bowel disease: a population-based study from Olmsted County, Minnesota. Gastroenterology. 2006;130(4):1039-1046.

86. Katsanos KH, Tatsioni A, Pedersen N, et al. Cancer in inflammatory bowel disease $15 y$ years after diagnosis in a population-based European collaborative follow-up study. J Crohns Colitis. 2011;5(5):430-442.

87. Jess T, Simonsen J, Jørgensen KT, Pedersen BV, Nielsen NM, Frisch M. Declining risk of colorectal cancer in patients with inflammatory bowel disease over 30 years. Gastroenterology. April 19, 2012. [Epub ahead of print.]

88. Jess T, Rungoe C, Peyrin-Biroulet L. Risk of colorectal cancer in patients with ulcerative colitis: a meta-analysis of population-based cohort studies. Clin Gastroenterol Hepatol. 2012;10(6):639-645.

89. Tang J, Sharif O, Pai C, Silverman AL. Mesalamine protects against colorectal cancer in inflammatory bowel disease. Dig Dis Sci. 2010;55(6): 1696-1703.

90. Pinczowski D, Ekbom A, Baron J, Yuen J, Adami H. Risk factors for colorectal cancer in patients with ulcerative colitis: a case-control study. Gastroenterology. 1994;107(1):117-120.

91. Bernstein CN, Nugent Z, Blanchard JF. 5-aminosalicylate is not chemoprophylactic for colorectal cancer in IBD: a population based study. Am J Gastroenterol. 2011;106(4):731-736.

92. Terdiman JP, Johnson LK, Kim YS, et al. Chemoprevention of colonic polyps with balsalazide: an exploratory, double-blind, placebocontrolled study. Dig Dis Sci. 2009;54(11):2488-2496.

93. Velayos FS, Terdiman JP, Walsh JM. Effect of 5-aminosalicylate use on colorectal cancer and dysplasia risk: a systematic review and metaanalysis of observational studies. Am J Gastroenterol. 2005;100(6):1345-1353.
Clinical Pharmacology: Advances and Applications

\section{Publish your work in this journal}

Clinical Pharmacology: Advances and Applications is an international, peer-reviewed, open access journal publishing original research, reports, reviews and commentaries on all areas of drug experience in humans. The manuscript management system is completely online and includes a very quick and fair peer-review system, which is all easy to use.

\section{Dovepress}

Visit http://www.dovepress.com/testimonials.php to read real quotes from published authors. 